\title{
A PEDAGOGIA HISTÓRICO-CRÍTICA NA TRAJETÓRIA HISTÓRICA E NOS FUNDAMENTOS TEÓRICOS DO CURRÍCULO PARA A REDE PÚBLICA MUNICIPAL DE ENSINO DE CASCAVEL/PR
}

\author{
Julia Malanchen $^{\mathrm{i}}$ \\ Universidade Estadual do Norte do Paraná (UENP) \\ Neide da S. D. Matos ii \\ Claudia Pagnoncelli iii \\ Secretaria Municipal de Educação de Cascavel (SEMED)
}

\begin{abstract}
RESUMO
A finalidade deste artigo é a de primeiramente relatar a trajetória histórica do processo de elaboração do Currículo para a Rede Pública Municipal de Ensino de Cascavel, na sequiência, expor os principais pressupostos que fundamentam este documento que se constitui em três volumes (Educação Infantil, Ensino Fundamental (Anos Iniciais) e Educação de Jovens e Adultos - Fase I) concluído em 2007 e implementado a partir de 2008. O documento tem como referencial teórico a epistemologia materialista históricodialética (MARX), a proposições da psicologia histórico-cultural (VIGOTSKY) e a pedagogia histórico-crítica (SAVIANI). Intenta-se também apresentar os pressupostos sobre a educação das pessoas com deficiências, afirmados nesse Currículo. À vista da implementação do referido documento, é exposto o processo de formação continuada desencadeado no município nos anos de 2008 a 2010, que buscou instrumentalizar os professores da Rede Municipal de Ensino para a compreensão e aplicação efetiva e gradativa do documento, que foi pela primeira vez na história, elaborado pela própria Rede e com discussões envolvendo os professores das escolas municipais.

Palavras-chave: Currículo; pedagogia histórico-crítica; Cascavel; formação continuada

\section{Historical-Critical Pedagogy in the history and theoretical foundations of the Public Education of Cascavel - PR}

\begin{abstract}
The purpose of this article is to report on the historical trajectory of the process of preparing the curriculum for the Municipal Public Education of Cascavel (PR) and to describe the assumptions underlying this document, broken into three volumes (Early Childhood Education, Elementary Education (Early Years) and Youth and Adult Education - Phase I) completed in 2007 and implemented from 2008. The article is theoretically based on the historical and dialectical method of materialism (Marx), cultural-historical psychology (Vygotsky) and historical-critical pedagogy (SAVIANI). This article is also intends to present the assumptions stated in the Education of Curriculum regarding people with disabilities. To conclude, it focuses on the process of ongoing education, mainly in the years 2008 to 2010, which intended to providing teachers of the Municipal School a gradual but effective implementation of the document. It was used there for the first time in history and prepared by the personal networking and discussions of teachers of municipal schools.
\end{abstract}

Keywords: Curriculum. Historical-critical pedagogy. Cascavel. Ongoing Education 


\section{Introdução}

Os objetivos deste trabalho são o de relatar o processo de elaboração do Currículo para a Rede Pública Municipal de Ensino de Cascavel $^{\text {iv }}$ na sequência, expor os principais pressupostos que fundamentam este documento, desmembrado em três volumes (Educação Infantil, Ensino Fundamental (Anos Iniciais) e Educação de Jovens e Adultos - Fase I) concluído em 2007 e implementado em 2008, que tem como referencial teórico, o método materialista histórico e dialético (MARX), consequentemente a psicologia históricocultural (VIGOTSKY) e a pedagogia histórico-crítica (SAVIANI), temos também por finalidade, apresentar os pressupostos afirmados nesse Currículo sobre a educação das pessoas com deficiências. Buscaremos no final do trabalho, apontar alguns encaminhamentos feitos pela Equipe Pedagógica da época para instrumentalizar os professores da Rede, no trabalho pedagógico a partir do documento elaborado.

A elaboração coletiva de um Currículo para a Rede significou discutir e definir os pressupostos teóricos que foram elaborados a partir da definição de um método que tem por objetivo orientar todo o trabalho realizado no espaço escolar. Pois compreende-se que todo Currículo aponta um homem a ser formado e orienta um caminho de construção social, ainda que não haja a explicitação da visão de mundo na qual esteja fundada. Assim,

A elaboração de um Currículo para a Rede Pública Municipal de Ensino de Cascavel se justifica pela necessidade de sistematizar um arcabouço teórico-metodológico que confira a direção e a conseqüente apropriação dos métodos deste conhecimento, uma vez que "se não temos suficiente clareza, segurança acerca dos fundamentos teóricos que nos orientam; se não paramos para refletir sobre eles, corremos o risco de agir contrariamente aos nossos objetivos (SED/ MS, 2000, p.12). (CASCAVEL, 2008, p. 9)

Ao refletirmos sobre o método definido, buscamos maior compreensão nos estudos realizados por Moraes. Para a autora, o método:

consiste em elevar-se à síntese de múltiplas determinações [...], um meio de o pensamento apreender o concreto, um meio de reproduzir esse concreto no processo do conhecimento. De modo algum este caminho se configura como um processo de gênese do próprio concreto. Ao contrário do que afirmam as ilusões idealistas, as categorias refletem a realidade, não a criam (MORAES, 2000, p. 33).

A opção pelo método materialista histórico e dialético na elaboração do Currículo teve como finalidade constituir uma unidade de direção ao trabalho pedagógico desenvolvido na Rede e, dessa maneira, cooperar para que a ação docente seja direcionada de forma intencional e coerente. Com esse fim, o método adotado:

privilegia o conhecimento da totalidade de relações nas quais o homem se envolve [...] considera o homem como aquele que é capaz de perceber que a construção de uma nova sociedade passa pelo conjunto de ações de todos os homens que lutam por objetivos comuns [...] valoriza o saber historicamente reproduzido e acumulado pelos homens (SEED/ PR, 1986, p.12). 
Saviani (1991), discutindo a necessidade do educador brasileiro passar do senso comum para a consciência filosófica na compreensão de sua prática educativa, aponta o método materialista histórico dialético como instrumento desta prática e explica, para isto, a superação da etapa de senso comum educacional (conhecimento da realidade empírica da educação), por meio da reflexão teórica (movimento do pensamento, abstrações), para a etapa da consciência filosófica (realidade concreta da educação, concreta pensada, realidade educacional plenamente compreendida).

Para Saviani, "o trabalho educativo é o ato de produzir direta e intencionalmente, em cada indivíduo singular, a humanidade que é produzida histórica e coletivamente pelo conjunto dos homens" (SAVIANI, 1995, p. 17).

Com essa compreensão trabalhar com o conhecimento num processo educativo intencional implica: reconhecer a objetividade e universalidade do conhecimento; reconhecer o caráter histórico deste conhecimento, o tratamento científico do conhecimento na organização do Currículo e a vinculação dos conteúdos com as exigências teóricas e práticas da formação dos indivíduos. (CASCAVEL, 2008, p.10)

A intencionalidade e o rigor na definição do método para o desenvolvimento da ação docente visam garantir que a escolav ${ }^{\mathrm{v}}$ cumpra verdadeiramente seu papel e não se perca em armadilhas criadas por correntes pedagógicas "imediatistas e pragmáticas" (DUARTE, 2004), que atrelam o significado e o sentido da aprendizagem dos conteúdos escolares ao utilitarismo alienante do cotidiano da sociedade capitalista. (CASCAVEL, 2008, p.10)

A opção pelo método materialista histórico dialético também se justifica por expressar o projeto de educação, sociedade e homem que os profissionais da educação da Rede apontaram em seus estudos e debates. Um projeto que compreende o desenvolvimento histórico dos homens a partir de um processo conflituoso, impulsionado pela luta de classes, num cenário amplamente marcado pela contradição entre o desenvolvimento das forças produtivas e as relações sociais de produção. (CASCAVEL, 2008, p.11)

Esta produção não foi uma tarefa fácil, visto que, estudar e buscar compreender o método materialista histórico e dialético, não é uma tarefa simples, e requer um sistemático esforço intelectual, além das condições objetivas de produção como: encontrar bibliografias e consultores que pesquisam e trabalhem nesta linha teórica, produzir de forma coletiva e conseguir a participação dos profissionais da escola, que não tem espaço de tempo em sua carga horária semanal.

Apesar de todos os obstáculos e contradições o Currículo foi elaborado e acreditase que seus fundamentos trazem a possibilidade de se construir a autonomia e as condições para a tomada de consciência da classe trabalhadora, tendo um enfoque principal no "o quê ensinar", aproximando os alunos da riqueza intelectual produzida historicamente. Neste documento busca-se esclarecer que a finalidade da escola deve determinar os métodos e processos de ensino-aprendizagem. Assim, a transmissão-apropriação do conhecimento sistematizado torna-se o foco da definição do saber escolar, portanto, o conhecimento científico deve ser o elemento central de referência para a organização do ensino.

A seguir relatamos o processo de elaboração do Currículo, entendendo que foi um período importante que deve ficar registrado na história do município de Cascavel, e que essa iniciativa, não seja entendida como última e única, mais a primeira de diversos debates e elaborações que a categoria dos professores deve realizar, pensando na qualidade do ensino que deve ser desenvolvido na escola pública. 


\title{
Um pouco da história da elaboração do Currículo para a Rede Pública Municipal de Ensino de Cascavel
}

No final da década de 1980 e inicio de 1990, especificamente em 1989, no Paraná, em razão da implementação do Ciclo Básico nas escolas públicas, foi elaborado e implementado um documento norteador para a Educação, o Currículo Básico para a Escola Pública do Estado do Paraná (1990), documento utilizado pela Secretaria Municipal de Educação de Cascavel (SEMED) até 2007.

O Currículo nesta época já trazia em sua fundamentação elementos do método materialista histórico e dialético, assim como da psicologia histórico-cultural e da pedagogia histórico-crítica. Este documento foi referência para todo o Estado durante quase duas décadas, sendo também um documento inovador e importante a nível nacional, visto que vários estados brasileiros, até hoje não possuem um Currículo definido, estudado e implementado com uma linha teórica coerente com a função da escola pública.

Coadunando com os pressupostos do Currículo existente, mas compreendendo a necessidade de retomar algumas discussões importantes ${ }^{\mathrm{vi}}$ assim como atualizar alguns elementos teórico-metodológicos, em 2004 a SEMED, em conjunto com diretores, coordenadores de escolas e Centros de Educação Infantil, da Rede, iniciaram algumas discussões com o objetivo de organizar o Ensino Fundamental de nove anos, elaborarem um Currículo para a Educação Infantil e a Educação de Jovens e Adultos que até então não existiam. Buscava-se com isso reafirmar o papel da escola que de acordo com Saviani (1995, p. 15)

existe, pois, para propiciar a aquisição dos instrumentos que possibilitam o acesso ao saber elaborado (ciência), bem como o próprio acesso aos rudimentos desse saber. As atividades da escola básica devem organizarse a partir dessa questão. Se chamarmos isso de Currículo, poderemos afirmar que é a partir do saber sistematizado que se estrutura o Currículo da escola elementar.

No ano de 2005, a SEMED, promoveu encontros com todos os coordenadores com os primeiros encaminhamentos para iniciar a elaboração de um Currículo próprio. O ponto de partida para a compreensão de um Currículo foi o estudo do Currículo do Estado do Paraná, sendo que os estudos realizados suscitaram a necessidade de maior aprofundamento teórico. Neste processo os coordenadores pedagógicos, por orientação da SEMED, distenderam as discussões ao interior das escolas, inicialmente com indagações simples e específicas, mas necessárias como: os alunos estão realmente aprendendo? O que estão aprendendo? Como estão aprendendo? Como estamos ensinando? Existe uma unidade de trabalho na rede municipal? De acordo com Zóia, (2007, p. 356):

\begin{abstract}
A proposição destas questões era a de discutir no interior da escola a educação que temos hoje, fazendo um diagnóstico da situação que a mesma se encontra, pois pensando em um processo de reestruturação curricular, que tem como intencionalidade a participação coletiva dos profissionais evolvidos, faz-se necessário que este grupo realmente perceba a importância e a necessidade dessa reestruturação.
\end{abstract}

A partir dessa reflexão e do debate, professores apontaram a necessidade de maior compreensão dos elementos norteadores de um Currículo como: a concepção das disciplinas, encaminhamento metodológico, conteúdos e avaliação. 
Nessa direção, além do estudo do Currículo aludido, a SEMED, recomendou algumas leituras, entre elas, textos ${ }^{\mathrm{vii}}$ que motivaram as discussões sobre: saber escolar, atividades essenciais e secundárias na escola, produção da existência humana, trabalho material e não material, trabalho educativo e função social da escola.

Estes estudos foram de suma importância, e por isso na sequência, a SEMED utilizando-se das paradas pedagógicas ${ }^{\text {viii }}$, desencadeou um trabalho nos espaços escolares, orientado com os seguintes questionamentos: que tipo de sociedade almejamos? Que homem almejamos? Que conhecimentos são necessários para formar este homem? Que tipo de educação? Que profissional? E que caminho seguir? "Os dados evidenciaram que os profissionais da educação têm clareza da educação que se pretende, em função das críticas que pontuaram quanto à educação que temos hoje" (ZÓIA, 2007, p. 356).

Para um trabalho de sistematização, os grupos nas escolas, responderam as seguintes questões: que educação temos? Que educação queremos? Por que e para quê queremos essa educação? Que proposta curricular pretendemos para essa educação? Quais são os dificultadores para que essa proposta possa se concretizar? ${ }^{\mathrm{x}}$

Ainda de acordo com Zóia, (2007, p. 357):

teoricamente é possível fazer a crítica e apresentar elementos evidenciadores de uma nova proposta, que trazem conceitos fundamentais, inclusive para se definir qual seria a concepção que estaria fundamentando a reelaboração da proposta curricular. É possível perceber, então, que os profissionais da educação apontam elementos claros quanto aos fundamentos filosóficos, psicológicos e pedagógicos que defendem e que acreditam. Tais informações são extremamente relevantes para equipe a da secretaria de educação que estará conduzindo o processo de reestruturação curricular.

Concomitante a este trabalho, a Associação dos Municípios do Oeste do Paraná (AMOP) encaminhava estudos para a construção de um Currículo para os municípios de sua abrangência, sendo que Cascavel participava das discussões com uma representatividade ${ }^{\mathrm{xi}}$, esta participação foi de grande relevância teórica, bem como de experiência prática para a elaboração pela SEMED de um Currículo próprio para a sua Rede, considerando que essa foi uma solicitação dos profissionais da educação que trabalham na mesma.

Em 2006, a equipe da SEMED, reorganiza os trabalhos, convidando professores e pesquisadores $^{\text {xii }}$ de universidades para contribuir nas discussões e elaboração do documento, buscando sempre manter o rigor na linha teórica adotada. Desta forma, conduziram-se momentos de estudos com estes professores, algumas vezes com todos os profissionais da rede ${ }^{\text {xiii }}$ e outras com os grupos específicos de professores que se inscreveram para participar desta elaboração, divididos nas disciplinas curriculares, e também em grupos para estudar e escrever elementos específicos da concepção teórica adotada, da Educação Especial, da Educação Infantil e da Educação de Jovens e Adultos.

A partir desses estudos foram delineados os fundamentos teóricos do Currículo, no quais estão definidos a concepção de sociedade, homem, trabalho, desenvolvimento humano, educação e educação escolar, de aprendizagem e ensino, avaliação, etc.

Assim, na medida em que os grupos produziam os textos, estes eram enviados as escolas, que se organizavam para realizar as leituras e sugerir alterações, respeitando a concepção de ensino adotada.

Em 2007 continuaram os estudos e elaborações escritas, neste ano foram concluídos os textos de cada disciplina ${ }^{\text {xiv }}$ assim como elementos específicos da etapa de Educação Infantil e da modalidade de Educação de Jovens e Adultos e Educação Especial. 
Neste ano o Currículo, ganha forma, e se estrutura em tópicos, e fica assim organizado: no primeiro tópico, abordam-se os Fundamentos Teóricos da Educação na Rede Pública Municipal de Ensino de Cascavel. O segundo tópico expõe os pressupostos teóricos para a educação de pessoas com deficiência. O terceiro e último tópico refere-se à organização curricular, com as seguintes disciplinas: Língua Portuguesa/Alfabetização, Matemática, História, Geografia, Ciências, Educação Física, Arte e Língua Estrangeira/Língua Espanhola, com sua concepção, encaminhamento metodológico, conteúdos e avaliação, esta organização das disciplinas é para o ensino fundamental Anos Iniciais, para a Educação Infantil, somente se retira a língua estrangeira. Para a Modalidade de Educação de Jovens e Adultos a organização seguiu a seguinte estrutura: Língua Portuguesa, Matemática, Estudos da Sociedade e da Natureza (História, Geografia e Ciências), Educação Física e Arte.

Assim, o resultado da produção foi organizado em três volumes (Volume I Educação Infantil, Volume II Ensino Fundamental (anos iniciais) Volume III Educação de Jovens e Adultos - fase I).

Explicitamos dessa maneira como foi o processo de elaboração coletiva do Currículo para a Rede Pública Municipal de Ensino de Cascavel, que teve seu inicio em 2004 e conclusão em 2007. A seguir buscamos expor de maneira mais específica alguns dos fundamentos teóricos que permeam os três volumes deste documento.

\section{Concepção de homem e sociedade presentes no Currículo}

Como citado anteriormente, o método materialista histórico e dialético é o que fundamenta o Currículo de Cascavel Este método, traz em seu bojo a compreensão de que o homem não se forma isoladamente, mas na relação com a natureza por meio do trabalho e com os outros seres da sua espécie. E que,

Ao satisfazer suas necessidades de produção da vida material, o homem interfere na natureza e a transforma. Esta intervenção tem um caráter dinâmico, pois as novas necessidades criadas possibilitam ao homem a produção de novos conhecimentos. (CASCAVEL, 2008, p.13).

De acordo com Markus (1974), conforme o homem adquire novas necessidades, e aos elaborar novos modos de produção, o ser humano o faz num modo novo e dentro de novas conexões, ele cita como exemplo os experimentos científicos, e afirma que tudo isso faz com que o homem chegue cada vez mais ao um saber completo do mundo dos objetos.

Compreende-se nesse sentido que além das necessidades que a natureza apresenta ao homem, ele amplia sua condição animal e no processo de humanização cria novas necessidades e produz meios para satisfação destas, como a linguagem e os meios de produção.

Tal humanização dá-se pelo trabalho, atividade humana por excelência, através da qual o homem se produz como homem. Ao intervir no mundo para garantir sua sobrevivência, o homem cria a própria vida humana, por isso o trabalho é a humanização do homem, sem o qual estaria no plano da vida animal. (CASCAVEL, 2008, p.11)

A humanização é deste modo, resultado da cultura material e intelectual historicamente acumulada. Por conseguinte, o homem como ser humanizado não é decorrência de características puramente biológicas, mas sim das relações que este 
estabelece com as formas de atividade socialmente existentes.

O homem não está evidentemente subtraído ao campo de ação das leis biológicas. O que é verdade é que as modificações biológicas hereditárias não determinam o desenvolvimento sócio-histórico do homem e da humanidade; este é doravante movido por outras forças que não as leis da variação e da hereditariedade biológicas. (LEONTIEV, 1978, 264).

Compreende-se com isso que fazer parte das relações estabelecidas coletivamente demanda assimilar as formas de atividade material e cultural historicamente produzidas. Quanto mais o indivíduo apropria-se da cultura material e intelectual elaborada, mais ele se humaniza. Portanto, para ser humano, não basta ter as mesmas características biológicas, é preciso apropriar-se do que a coletividade constrói para aprimorar a produção da vida material, da cultura. Conforme o Currículo de Cascavel:

Ao produzir sua vida material, este homem não o faz sozinho, o faz socialmente. Também não é possível compreendê-lo de forma ahistórica. Isto significa dizer que uma determinada forma de organização social advém de um encadeamento das forças produtivas historicamente produzidas. Assim, um específico momento histórico deve ser concebido articulado às forças produzidas pelas gerações que o precederam. Desta forma, o desenvolvimento de determinadas forças produtivas, decorre do resultado de um processo sócio-histórico cumulativo, e não como uma conquista que se deve estritamente ao plano individual. (CASCAVEL, 2008, p. 16).

Este processo sócio-histórico tem como determinante principal o desenvolvimento das forças produtivas materiais que incidem diretamente no modo como tais indivíduos estabelecem essas relações. Marx, coloca que,

[...] cada geração continua por um lado, o modo de atividade que lhe foi transmitido, mas em circunstâncias radicalmente transformada; e, por outro, modifica as antigas circunstâncias, dedicando-se a uma atividade radicalmente diferente. (MARX, 1996, p.46).

É mister a compreensão de que a organização da sociedade com base no modo de produção extrapola o campo da economia, constituindo-se em níveis diferenciados e interligados - o Econômico (relação de produção); o Político (leis, Estado) e o Ideológico (ideais, costumes e religião). Nestas relações, há um movimento interno dinâmico que determina as características da sociedade, possibilitando a compreensão de que a escola sozinha não garante a transformação social, mas tem uma participação importante e única considerando as condições subjetivas de força, somadas as demais.

\section{Concepção de Educação e Educação Escolar}


A educação é a forma cultural de transmitir às novas gerações os conceitos elaborados ao longo da história na relação dos homens entre si e com a natureza, na produção da sua existência. Neste sentido, afirma Saviani:

[...] o objeto da educação diz respeito, de um lado, à identificação dos elementos culturais que precisam ser assimilados pelos indivíduos da espécie humana para que eles se tornem humanos e, de outro lado e concomitantemente, à descoberta das formas mais adequadas de atingir esse objetivo (SAVIANI, 1991, p. 21).

Com essa compreensão, a tarefa da educação escolar é mediar a constituição dos indivíduos e a produção da cultura universal humana, num processo educativo intencional e portando direcionado, planejado, por meio do qual o indivíduo é instigado a se apropriar das formas mais desenvolvidas do saber objetivo elaborado historicamente pelo homem. Isto significa que o conhecimento científico, artístico e filosófico produzido pela humanidade expressa a elaboração teórica sobre os fenômenos sociais e naturais, não ocorre de forma espontânea ou sem intencionalidade, exige um processo articulado, intencional e direcionado.

Desta forma, a escola não deve ignorar o conhecimento cotidiano, mas também não pode ser refém desse conhecimento. Ela deve sempre desenvolver um trabalho educativo com o objetivo de superar o conhecimento do cotidiano, como há tempos Saviani afirmou, passar do senso comum para a consciência filosófica.

No Currículo de Cascavel, defende-se que no processo educacional estão envolvidos ativamente dois sujeitos: o professor e o aluno, ambos com funções diferentes. Assim,

ao aluno cabe apreender os conteúdos mediados pelo professor e a este conhecer os elementos que estão envolvidos no processo de ensino, para que possa direcionar sua ação de forma mais coerente. $\mathrm{Na}$ medida em que os conceitos são apropriados, as funções psicológicas superiores são formadas por meio de um relacionamento entre os fatores biológicos e culturais, ou seja, na e pela história social dos homens. Para Vygotski (1993, VOL. II), tais funções, tidas como essencialmente humanas, são originárias da interação homem-mundo-cultura, interação essa mediada por instrumentos e signos, criados ao longo da história sócio-cultural da humanidade. (CASCAVEL, 2008 p.40).

Neste cenário, a instituição escolar tem uma função política essencial, que é o de lutar pela socialização do conhecimento científico, para que este não fique somente nas mãos da classe dominante, mas sim, que a educação possa cada vez mais permitir o enriquecimento intelectual de todos os indivíduos.

A finalidade da escola é, portanto, garantir que os conhecimentos ultrapassem o pragmatismo da vida cotidiana e aproximar os indivíduos da produção cultural mais elevada já produzida pela humanidade. Afirma-se com isso, que entende-se que a escola existe para propiciar aquisição dos instrumentos que possibilitem o acesso ao saber elaborado (ciência), bem como o próprio acesso aos rendimentos desse saber (SAVIANI, 2003).

De acordo com o Currículo de Cascavel (2008), a transmissão-apropriação do conhecimento sistematizado torna-se o foco da definição do saber escolar, portanto, o 
conhecimento científico deve ser o elemento central de referência para a organização do ensino na escola pública.

Nesse sentido a escola, o professor, os conteúdos escolares são a todo momento reafirmados, como, imprescindíveis para que a classe trabalhadora seja instrumentalizada, desalienada, e que isso pode acontecer com o acesso ao conhecimento científico. Almejase que isso possibilite que esta classe se organize por meio do conhecimento e busque a transformação social. Pois uma sociedade igualitária e justa só será possível por meio da superação de um modelo social pautado no capital, num modelo de sociedade de classes, e no acesso de apenas uma minoria aos bens materiais e culturais acumulados e produzidos pela humanidade. (MALANCHEN, 2011).

\section{Políticas e pressupostos para a educação das pessoas com deficiências}

Neste item, temos por objetivo realizar algumas considerações pertinentes a gestão das políticas públicas de educação especial no município de Cascavel/PR, assim como também, explicitar os pressupostos que norteiam o trabalho educativo para as pessoas com deficiência, no Currículo da Rede.

A Educação Especial é considerada como modalidade oferecida preferencialmente no sistema regular de ensino, compreendendo uma rede de serviços de apoio e uma diferenciação de serviços especializados, como pode ser observado na Lei 9394/96 (BRASIL, 1996).

No âmbito da Rede Pública Municipal de Ensino Cascavel os alunos recebem Atendimento Educacional Especializado (AEE) e pelo Sistema Único de Saúde - SUS, por meio da rede de apoio, atendimento clínico especializado. O AEE se destina a alunos com deficiência física, mental, sensorial (visual e pessoas com surdez), alunos com transtornos globais do desenvolvimento e com altas habilidades (que constituem o público alvo da Educação Especial).

É importante destacarmos que são oferecidos os seguintes atendimentos nas escolas comuns: Salas de Recursos (SR) e Salas de Recursos Multifuncionais (SRM) e, em espaços próprios, mantidos pela rede municipal de ensino: Centro de Apoio Pedagógico para Atendimento à Deficiência Visual - CAP e Centro de Capacitação de Profissionais da Educação e de Atendimento às Pessoas com Surdez - CAS.

A Rede de Apoio é ofertada pelos serviços de saúde: Unidade Básica de Saúde UBS, Centro de Atenção Psicossocial Infantil (CAPSI), Centro de Atenção Psicossocial Álcool e Droga (CAPSAD), Centro de Atendimento Especializado à Saúde do Neonato Criança e Adolescente (CEACRI) e Centro de Reabilitação (baixa, média e alta complexidade).

O Atendimento Educacional Especializado é organizado para suprir as necessidades de acesso ao conhecimento e à participação dos alunos com deficiência e dos demais que são público alvo da Educação Especial, nas escolas comuns.

Nesse sentido a constituição do atendimento educacional às pessoas com deficiências resulta de um processo de lutas, de conquistas, ou seja, de um processo histórico.

Compreendendo que, mesmo os sujeitos com deficiência necessitando de metodologia adaptada, recursos específicos e instalações adequadas, a Educação Especial constitui-se em Educação, suas finalidades são as mesmas, tornar indivíduos com e sem deficiência capazes de agirem de modo mais independente possível. 
Assim, ao considerar o pressuposto de que toda pessoa tem direito a se apropriar do acervo científico, artístico e filosófico, produzido pela humanidade, a escola representa a forma pela qual este direito pode ser exercido. Isso significa que

[...] a unidade da espécie humana parece ser praticamente inexistente não em virtude das diferenças de cor da pele, da forma dos olhos ou de quaisquer outros traços exteriores, mas, sim, das enormes diferenças nas condições e no modo de vida, da riqueza da atividade material e mental, do nível de desenvolvimento das formas e das aptidões intelectuais (LEONTIEV, 1978, p. 274).

A individualidade ou diferença de cada membro da espécie humana resulta da relação dele com o gênero humano, da apropriação da cultura acumulada historicamente pela humanidade. A formação da individualidade tem início no nascimento e tem continuidade por toda a vida [...] "as aptidões e caracteres especificamente humanos não se transmitem de modo algum por hereditariedade biológica, mas são adquiridos no decurso da vida por um processo de apropriação da cultura criada pelas gerações precedentes" (LEONTIEV 1978, p. 267). Compreendemos, a partir desses pressupostos, que ter as características biológicas definidoras da espécie humana, não basta para ser humanizado, é necessário apropriar-se do que a coletividade produziu e produz para garantir e melhorar a vida material.

Desta forma, compreende-se que o processo educacional pode elevar o homem da sua condição primitiva à forma cultural, ultrapassando o determinismo biológico, entendendo que a deficiência não retira do homem a sua possibilidade de humanização, pois, não é em si uma doença, mas uma condição com a qual a pessoa convive.

Para tanto, os estudos de Vigotski (1997) nos apontam que a deficiência é um fato biológico, porém o professor não tem que atuar no fato, mas nas consequiências sociais deste, seu papel incide no ensino e, desta forma, no desenvolvimento de vias colaterais.

Sob este aspecto, a deficiência não é fator impeditivo do desenvolvimento e sim o que implica sob tal condição, são as vias diferentes para ocorrer o desenvolvimento. $\mathrm{O}$ aluno terá acesso aos mesmos conteúdos que qualquer outra criança, mas por caminhos diferentes daqueles realizados pelos demais, oportunizando a este, como a qualquer outro indivíduo, passar do desenvolvimento primitivo ao cultural, pois o princípio de desenvolvimento cognitivo e da personalidade é o mesmo, para a criança com ou sem deficiência.

A superação do biológico se constitui no processo de apropriação da produção cultural universal "a cultura e o meio ambiente refazem uma pessoa não apenas por lhe oferecer determinado conhecimento, mas pela transformação da própria estrutura dos seus processos psicológicos" (VYGOTSKY; LURIA, 1996, p. 228). Os processos naturais pelos quais a criança inicia sua vida, rapidamente se modificam dando origem a uma forma inteiramente nova, onde os constituintes naturais biológicos transformam-se em processos complexos, formados como resultado da influência cultural e, de uma série de condições resultantes da relação ativa da criança em seu meio social.

Para tanto, a educação da pessoa com deficiência deve partir do pressuposto de que simultaneamente com a deficiência existem as possibilidades de compensação deste "limite" e que são as possibilidades que devem ser incluídas na prática educativa, utilizando-se de metodologias, recursos e procedimentos diferenciados, pois "na essência, não existe diferença no enfoque educativo da criança com defeito da criança normal, nem na organização psicológica de sua personalidade" (VIGOTSKI, 1997, p. 44). 


\section{E para concluir...}

Após a explicitação do processo de elaboração do Currículo de Cascavel e de seus principais fundamentos, destacamos que compreendemos que o trabalho não terminou com a conclusão do documento escrito. Pois segundo Zóia:

Deve-se ter clareza de que o processo não termina com o documento pronto, mas há necessidade da organização e o compromisso da mantenedora quanto aos aspectos financeiros englobando os aspectos físicos, materiais, pedagógicos, humanos, inclusive a capacitação continuada dos profissionais da educação. (2007, p. 359).

O desafio subseqüente, deste modo, é o de que, o Currículo seja efetivado na prática pedagógica nas salas de aula, por todos os professores da Rede. Isto porque,

compreende-se que a prática do professor em sala de aula não é puramente prática, nem deve ser puramente teoria, mas para que haja a efetivação de uma verdadeira práxis pedagógica é necessário a indissociabilidade entre as mesmas. Isso se faz possível pela ação pedagógica comprometida com o aluno, com a qualidade de sua aprendizagem, pelo estudo e pesquisa continuada de cada professor individualmente e nos grupos de estudos organizados pela escola e pela Secretaria Municipal de Educação. (MALANCHEN, 2011, p.77-78)

Com essa intenção, para os anos de 2008 a 2010, no Plano de ação do Departamento Pedagógico da SEMED, foi organizada uma formação continuada para todos os profissionais das escolas. A carga horária planejada teve como finalidade a fundamentação para o desenvolvimento do trabalho pedagógico a partir do novo Currículo.

Com esse objetivo, a SEMED, ofertou cursos para os 1214 professores, incluindo diretores e coordenadores pedagógicos, professores de classe especial e sala de recursos, professores de artes, espanhol, educação física, reforço escolar e de $1^{\circ}$ ao $5^{\circ}$ ano, 55 monitores de biblioteca, 45 instrutores de informática e 315 profissionais dos Centros Municipais de Educação Infantil. Esse número de profissionais atende aproximadamente 23.000 alunos do Ensino Fundamental e 2300 alunos na Educação Infantil.

Esta formação continuada foi dividida em dois momentos. O primeiro momento foi realizado pelas coordenadoras de cada disciplina da $\operatorname{SEMED}^{\mathrm{xv}}$ (Geografia, História, Língua Portuguesa, Matemática, Artes, Educação Física, Língua Estrangeira - Espanhol e Ciências) que organizaram estudos teóricos para compreensão do objeto de ensino e objetivos de cada disciplina, afirmando a importância de aprofundar e garantir o objeto de cada uma, sem tentar fazer junções forçadas de uma com outra, sem devido aprofundamento dos conceitos científicos que as envolvem. Reforçando que o Currículo de Cascavel, não trabalha numa perspectiva interdisciplinar, pois,

entende-se que os estudos interdisciplinares não devolvem, por si, a totalidade do conhecimento, porque não se trata de fazer uma junção forçada das partes para compreender o todo [...] Dessa forma o trabalho pedagógico neste currículo tem por objetivo a 
apreensão da totalidade do conhecimento que dar-se-á num movimento contrário, ou seja perceber nas partes a totalidade. Nesse sentido, na ação pedagógica, mesmo com conteúdos semelhantes às diferentes disciplinas tem objetos de ensino distintos que precisam ser garantidos. Um exemplo disso é o conteúdo dia e noite, que tem diferentes objetivos ao ser ensinado nas disciplinas de: matemática, ciências ou geografia. Portanto, é relevante destacar que a tentativa de relacionar as diferentes disciplinas e a totalidade do conhecimento não pode se separada do conjunto da teoria marxista que significa (buscar compreender os mecanismos de produção do conhecimento em sua natureza, seu desenvolvimento, sua história e a sua consistência em sua materialidade.) (MALANCHEN, 2011, p 76-77).

O segundo momento da formação focou a questão da compreensão dos conteúdos e os devidos encaminhamentos metodológicos, portanto foram e continuam sendo realizadas oficinas pedagógicas que envolvem a elaboração e a compreensão de como realizar o plano de aula, buscando articular a prática pedagógica com os pressupostos do novo Currículo.

Esta formação nas disciplinas tem sido realizada com todos os anos do Ensino Fundamental, com os professores da Educação de Jovens e Adultos e também com os professores que trabalham com maternal e pré-escola nos Centros Municipais de Educação Infantil (CMEI). Para os professores que trabalham com o Berçário nos CMEI, foi organizada a formação com profissionais da saúde para formá-los no sentido de trabalhar a questão da estimulação: gustativa, olfativa, visual, auditiva e a questão do desenvolvimento motor, neurológico e da linguagem. Portanto, os mesmos têm recebido formação com fisioterapeutas, fonoaudiólogas, psicólogos, enfermeiras, neuropediatras, pediatras ${ }^{\mathrm{xvi}}$, entre outros.

As dificuldades existem e são muitas tanto de ordem política e pedagógica, bem como de questões técnicas, para efetivar este Currículo, mas esses fatores tem sido imprescindíveis para fortalecer a efetivação de um documento coerente e que buscou o envolvimento de todos em sua elaboração e agora em sua implementação.

Acreditamos que os resultados positivos que almejamos, devem vir a médio e longo prazo, representado na compreensão dos professores do trabalho educativo que devem desenvolver e na aprendizagem qualitativa dos alunos, bem como em melhores condições de ensino e aprendizagem nas unidades escolares, que o poder público deve garantir.

Destacamos que este Currículo tem sido objeto de estudo em várias universidades, em território nacional, e são várias as secretarias municipais que entram em contato com a SEMED de Cascavel, para obter informações e conhecer como foi o processo. Além disso, o mais importante, é que temos uma Rede de ensino empenhada na aplicação deste documento, e quiçá, os resultados se efetivem em um menor espaço de tempo. Para encerrar fazemos coro a Saviani que afirma:

[...] o quadro que se nos descortina no limiar do terceiro milênio: superação do capitalismo ou destruição da humanidade e do planeta. Assim, a luta pela superação do capitalismo coincide com a luta em defesa da humanidade em seu conjunto. Para tanto, a consciência da situação, embora não suficiente, é uma condição prévia, necessária e indispensável. E o desenvolvimento dessa consciência implica um trabalho educativo sem o qual resultará 
impossível a mobilização da população para a realização das transformações necessárias. (SAVIANI, 1994, p. 103).

Dessa forma compreendemos que a apreensão sistematizada, dos conteúdos científicos, pode contribuir para a humanização do homem na medida em que, com maiores condições de organizar o pensamento e estabelecer relações ele se torna mais autônomo e consciente das relações sociais em que está posto.

Reafirmamos, nesse sentido que a prática educativa que se propõe no Currículo de Cascavel, é voltada para uma educação que considere o caráter histórico do homem, educando-o para transformar sua consciência, seu intelecto, para que pela sua práxis transforme sua própria história. A ação do professor deve "estabelecer conscientemente a mediação entre o cotidiano do aluno e as esferas não-cotidianas da vida social" (DUARTE, 2001, p. 58).

\section{Referências}

BRASIL, Diretrizes Curriculares do Ensino Fundamental foram instituídas por meio da resolução da CEB nº 2 de 07 de abril de 1998.

BRASIL. Ministério da Educação. Lei de Diretrizes e Bases da Educação Nacional - LDB $\mathrm{n}^{\circ}$ 9.394/96. 20 de dezembro de 1996.

CASCAVEL (PR). Secretaria Municipal de Educação. Currículo para Rede pública municipal de ensino de Cascavel. Cascavel, PR: Ed. Progressiva, 2008.

DUARTE, Newton. Formação do indivíduo, consciência e alienação: o ser humano na psicologia de A. N. Leontiev. Campinas - SP: Caderno Cedes, vol. 24 n. 62, 2004.

Educação Escolar, Teoria do Cotidiano e a Escola de Vigotsky. Campinas, SP: Autores Associados, 2001.

. Vigotski e o "aprender a aprender" crítica às apropriações neoliberais e pósmodernas da teoria vigotskiana. Autores Associados, Campinas SP, 2004.

LEONTIEV. A. N. O desenvolvimento do psiquismo. Lisboa: Livros Horizontes, 1978.

MALANCHEN, Julia. Alguns elementos para compreender os principais fundamentos do currículo para a Rede Pública Municipal de Ensino de Cascavel e o processo de formação continuada. In.: ORSO, Paulino José; et al (orgs). Educação e Sociedade: Uma relação desafiadora. Cascavel: Edunioste, 2011.

MARKUS, Gyorgy. Teoria do conhecimento do jovem Marx. Coleção pensamento crítico, vol. 1. Tradução de Carlos Nelson Coutinho, RJ - Paz e Terra, 1974.

MARX, Karl ; ENGELS, Friedrich. A ideologia alemã (Feuerbach). 10ª Ed. Tradução de José Carlos Bruni e Marco Aurélio Nogueira. São Paulo: HUCITEC, 1996.

MORAES, Maria Célia Marcondes de. Dupla problemática do objeto da história: ontológica e Metodológica. In: MORAES, Maria Célia Marcondes de. Reformas de ensino, modernização administrada. A experiência de Francisco Campos anos vinte e 
trinta. Florianópolis: UFSC, Centro de Ciências da Educação, Núcleo de publicações. 2000. (teses NUP).

PARANÁ, Currículo Básico para a escola pública do Estado do Paraná. Seed: 1990.

SAVIANI, Dermeval. Desafios para a construção coletiva da ação supervisora: uma abordagem histórica. Revista Idéias, nº 24, 1994.

SAVIANI, Dermeval. Pedagogia histórico-crítica: Primeiras aproximações. São Paulo: Autores Associados, 1995. $\overline{1996 .}$

. Educação do senso comum a consciência filosófica. Campinas: Autores Associados,

Escola e Democracia. Campinas: Autores Associados, 1991.

SEED/PR. Avaliação, sociedade e escola. Fundamentos para reflexão. (org. Lízia Helena Nagel) Curitiba, 1986.

VYGOTSKI, L. S. Obras Escolhidas II. Madrid, Centro de publicaciones Del M.E.C. y Visor Distribuciones, 1993.

VYGOTSKY, L.S; LURIA, A.R. Estudos sobre a história do comportamento: o macaco, o primitivo e criança. Trad. Lolio Lourenço de Oliveira. Porto Alegre: Artes Médicas, 1996.

VIGOTSKI, Liev Semiónovich. Obras escogidas: fundamentos de defectología. Tomo V. Habana: Editorial Pueblo y Educación, 1997.

ZÓIA, Elvenice Tatiana. Proposta Curricular: o Desafio da Reestruturação Coletiva Limites e Possibilidades. Anais do Seminário Nacional Interdisciplinar em Experiências Educativas - SENIEE, no ano de 2007 na Unioeste - Campus de Francisco Beltrão.

\footnotetext{
${ }^{\mathrm{i}}$ Mestre em Educação, UFSC/SC e doutoranda em Educação Escolar na UNESP/Araraquara. Professora Assistente do Curso de Pedagogia da UENP - Universidade Estadual do Norte do Paraná. Integrante e Líder do GEPEM (Grupo de Pesquisas em Estudos Marxistas) na UENP. Integrante do Grupo de Pesquisa Estudos Marxistas em Educação - UNESP/Araraquara/SP.

ii Mestre em Educação, UNIOESTE/Cascavel/PR, Coordenadora do Centro de Educação Paulo Freire na Secretaria Municipal de Educação de Cascavel. Integrante do Grupo de Pesquisa Histedopr/Unioeste.

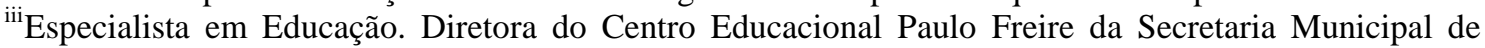
Educação de Cascavel/PR.

${ }^{\text {iv }}$ Doravante Rede.

v Neste artigo quando nos referimos à escola, nos referimos a todo espaço educacional, portanto aos Centros Municipais de Educação Infantil e aos Centros de atendimento a pessoa surda e cega, ao Centro de Educação de Jovens e Adultos, etc.

${ }^{\text {vi }}$ A SEMED também tinha a compreensão e a preocupação de buscar uma unidade nos trabalhos da Rede, pois reconhecia a existência de um ecletismo teórico na prática dos professores que acabavam por utilizar os parâmetros curriculares nacionais, junto com o Currículo básico do Paraná. Para saber mais, consultar monografia de CHINI, 2003 que realizou uma pesquisa e análise, no curso de especialização latto sensu - Fundamentos da Educação da Unioeste, que comprovam esta afirmação.

vii ANDERY, M. A. et al. Olhar para história: caminho para compreender a ciência hoje. In: ANDERY, M. A. et al. Para compreender a ciência: uma perspectiva histórica. Rio de Janeiro: Tempo: São Paulo:
} 
EDUC, 1988; ENGELS, Friedrich. Sobre o papel do trabalho na transformação do macaco em homem; EMER, Ivo Oss. Correntes Filosóficas, mimeo. PALANGANA, Isilda. Trabalho, linguagem e consciência: uma mediação que fundamenta a prática escolar; VYGOSTSKY, Lev. Internalização das funções psicológicas superiores. In: VYGOSTSKY, Lev. A Formação social da mente: SP: Martins Fontes, 2003; VYGOSTSKY, Lev. Interação entre aprendizado e desenvolvimento. In: A Formação social da mente: SP: Martins Fontes, 2003; SAVIANI, Dermeval. Sobre a natureza e a especificidade da educação. In; SAVIANI, Dermeval. Pedagogia histórico-crítica. SP: Autores Associados, 2005; SAVIANI, Dermeval. A Filosofia na formação do educador. In: SAVIANI, Dermeval. Do senso comum à consciência filosófica. SP: Autores Associados, 1993.

viii Dias previstos no calendário escolar para formação continuada dos professores nas escolas.

ix Além da reflexão a partir destas questões foram indicadas as leituras de documentos legais que respaldam a educação como a LDB 9394/1996 e as Diretrizes Curriculares Nacionais de 1998, assim como leitura do Plano Nacional de Educação e do Plano Municipal de Educação.

$x$ As respostas a estes questionamentos foram tabulados pela SEMED, e analisados e publicado em forma de artigo, no Anais do Seminário Nacional Interdisciplinar em Experiências Educativas - SENIEE, no ano de 2007 na Unioeste - Campus de Francisco Beltrão, pela professora Elvenice Tatiana Zóia, que fez parte da equipe pedagógica da SEMED e coordenou esses trabalhos.

${ }^{x i}$ Participaram do processo na AMOP, aproximadamente 135 pessoas, sendo, coordenadores, professores e equipe da SEMED.

xii Assessoria Geral em 2006 prof ${ }^{a}$ Dra Lílian Faria Porto Borges; assessoria Geral 2007: prof. Dr. Newton Duarte; consultores da disciplina de Língua Portuguesa: prof ${ }^{a}$ Dra Ligia Regina Klein em 2006 e prof $^{a}$ Dra Lourdes Kaminski Alves em 2007; língua estrangeira - espanhol: prof ${ }^{a}$ Ms. Adriana Aparecida Figueiredo Fiuza, matemática: 2006 prof. Ms. Carlos Petronzelli, em 2007 prof ${ }^{a}$ Dra Tânia Stella Bassoi, Ciências: prof. Ms. Carlos Petronzelli, história: prof $^{a}$ Dra Sandra Regina Ferreira de Oliveira; Arte: Prof ${ }^{a}$ Ms. Cristiane Denardi, Educação Física: prof. Ms. Alexandre Salomão; Geografia: prof ${ }^{a}$ Dra Angela Massumi Katuta, Educação Especial: PEE da Unioeste em 2006 e prof ${ }^{a}$ Dra Sonia Mari Shima Barroco em 2007, na Educação Infantil: prof ${ }^{a}$ Ms. Maria Cecilia Braz Ribeiro de Souza em 2006 e Prof ${ }^{a}$ Dra Alessandra Arce em 2007e na Educação de Jovens e Adultos prof ${ }^{a}$ Dra Monica Ribeiro da Silva.

xiii Foram organizados momentos na Rede, nos quais os professores participaram de encontros com a prof $^{a}$ Dra Ligia Regina Klein da UFPR, Prof ${ }^{a}$ Dra Lilian Faria Porto Borges e a prof ${ }^{a}$ Dra. Aparecida Favoreto, da Unioeste, que expuseram sobre o Método adotado no Currículo e categorias do marxismo.

${ }^{\text {xiv }}$ Composto por concepção e objeto de ensino, encaminhamentos metodológicos, conteúdos, avaliação e critérios de avaliação.

${ }^{x v}$ Participaram também desse primeiro momento como ministrantes dessa formação, professores das universidades, alguns deles foram os consultores da elaboração do currículo.

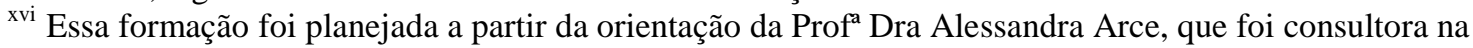
elaboração do currículo de educação infantil.

Recebido em setembro de 2011

Aprovado em março de 2011 